\title{
Impact of Massage Therapy on Fatigue, Pain, and Spasticity in People with Multiple Sclerosis: a Pilot Study
}

\author{
Deborah Backus, PT, PhD, * Christine Manella, PT, MT, \\ Anneke Bender, MPT, Mark Sweatman, PhD \\ Shepherd Center, Atlanta, GA, USA
}

\begin{abstract}
Background: Multiple sclerosis (MS) is a chronic, immune-mediated, inflammatory disease that leads to fatigue, pain, and spasticity, as well as other sensorimotor and cognitive changes. Often traditional medical approaches are ineffective in alleviating these disruptive symptoms. Although about one-third of surveyed individuals report they use massage therapy (MT) as an adjunct to medical treatment, there is little empirical evidence that MT is effective for symptom management in people with MS.
\end{abstract}

Purpose: To measure the effects of MT on fatigue, pain, spasticity, perception of health, and quality of life in people with MS.

Setting: Not-for-profit long-term care facility.

Participants: Twenty-four of 28 enrolled individuals with MS (average age $=47.38, \mathrm{SD}=$ 13.05; 22 female) completed all MT sessions and outcome assessments.

Research Design: Nonrandomized, pre-post pilot study.

Intervention: Standardized MT routine one time a week for six weeks.

Main Outcome Measure(s): Modified Fatigue Index Scale (MFIS), MOS Pain Effects Scale (MOS Pain), and Modified Ashworth Scale (MAS). Secondary outcome measures: Mental Health Inventory (MHI) and Health Status Questionnaire (HSQ).

Results: There was a significant improvement in MFIS $(p<.01)$, MOS Pain $(p<.01)$, MHI $(p<$ $.01)$, and HSQ $(p<.01)$, all with a large effect size (ES) (Cohen's d $=\mathbf{- 0 . 7 6}, \mathbf{1 . 2 5}, \mathbf{0 . 9 3}, \mathbf{- 1 . 0 1}$, respectively). There was a significant correlation between change scores on the MFIS and the MOS Pain ( $r$ $=0.532, p<.01)$, MHI $(r=-0.647, p<.01)$, and subscales of the HSQ (ranging from $r=\mathbf{- 0 . 5 1 9}$, to $-0.619, p<.01)$.

Conclusions: MT as delivered in this study is a safe and beneficial intervention for management of fatigue and pain in people with MS. Decreasing fatigue and pain appears to correlate with improvement in quality of life, which is meaningful for people with MS who have a chronic disease resulting in long-term health care needs.
KEY WORDS: multiple sclerosis; therapeutic massage; fatigue; pain; spasticity; symptom management

\section{INTRODUCTION}

Multiple sclerosis (MS) is a chronic, immunemediated, inflammatory disease of the central nervous system affecting over two million people world-wide. (1) The different patterns of inflammation, scarring, demyelination, and axonal damage that occur throughout the brain and spinal cord lead to varying symptoms that ultimately limit function and lead to disability. The resulting loss of independence and restrictions on recreational, vocational, and social activities, leads to a progressive decline in quality of life. While disease-modifying therapies may prevent or slow the progression of the disease, many symptoms remain, even with the use of these medications. ${ }^{(2)}$

Fatigue, pain, and spasticity are three disruptive symptoms in people with MS. Fatigue is the most commonly reported and affects daily activities and employment in over half of people with MS, ranging from $53 \%-87 \% .^{(3-9)}$ Pain, too, affects a large number of people with MS, anywhere from $30 \%$ to $90 \%$, depending on the study and the participant characteristics. $^{(10-13)}$ About $80 \%$ of people with MS report they have spasticity, or an increase in response to stretch and movement that is disruptive to everyday function, personal care, and mobility. ${ }^{(14-16)}$ As fatigue, pain, and spasticity increase in people with MS, mobility and everyday tasks become more difficult and quality of life (QOL) decreases. ${ }^{(17-19)}$ Interventions are needed to address these symptoms without side effects, in order to improve QOL in people with MS, especially given that they are expected to live a nearly full lifespan with this chronic condition. ${ }^{(16)}$

Approximately a third of surveyed individuals with MS report they use massage therapy (MT) as an adjunct to their medical treatment, often because conventional treatments are not effective in managing their symptoms. ${ }^{(20,21)}$ While various lines of research demonstrate that MT can improve QOL in people with $\mathrm{MS},{ }^{(21-25)}$ and decrease fatigue, pain, and spasticity in other patient populations, ${ }^{(26-33)}$ there is little empirical 
evidence supporting MT for symptom management. The purpose of this study was to measure the effects of six weeks of a standardized massage routine on fatigue, pain, spasticity, perception of health, and QOL in people with MS. Our main hypothesis was that MT would decrease participant complaints of fatigue, pain, and spasticity. Secondarily, we hypothesized that reduction in these impairments would lead to improved perception of health and QOL.

\section{METHODS}

This is a nonrandomized, pre-post design pilot study. This study was approved by the Research Review Committee (RRC) of the Shepherd Center prior to initiation of any study procedures.

\section{Participants}

We recruited any individual with medically confirmed MS who did not have medical complications that would affect their safety with receiving MT. Individuals were excluded if they had any of the following: unmanaged DVT; uncontrolled hypertension; unstable fractures; other neurological injury or disease; pregnant or trying to get pregnant; received MT in the past six months; weight exceeds $350 \mathrm{lbs}$. (due to capacity of equipment); unable to get out of wheelchair to safely transfer to massage table; unable to be safely and comfortably positioned on a massage table in order to receive the standardized massage routine.
Participants were recruited by word of mouth, RRC-approved fliers, and through the patient database at the Shepherd Center in Atlanta, Georgia. We aimed to enroll 25 participants; thus, if a participant dropped out of the study, we recruited another in order to complete data collection on 25 people with MS. All participants received the intervention.

\section{Outcome Measures}

The following outcome measures were collected before and after completion of the six-week intervention phase, but not immediately after a massage session. All were collected by the study coordinator, except for the Modified Ashworth Scale (MAS), ${ }^{(34)}$ which was performed by a trained physical therapist.

The primary outcome measures were the Modified Fatigue Index Scale (MFIS), ${ }^{(35-38)}$ the Modified Ashworth Scale (MAS; spasticity), ${ }^{(34)}$ and the MOS Pain Effects Scale Secondary outcome measures included assessment of perception of health and quality of life using subscales of the MS QLI. ${ }^{(38)}$ Outcome measures are described in Table 1.

\section{Massage Therapy Intervention}

A specific routine of $\mathrm{MT}^{(39)}$ was designed by two study investigators who are licensed physical therapists and licensed massage therapists. Tables 2 and 3 provide details regarding the specific routine. In general, the MT routine consisted of a combination of effleurage, petrissage, friction, and static compression strokes. ${ }^{(40)}$ Effleurage (E) was defined as using a

Table 1. Outcome Measures

\begin{tabular}{|c|c|c|}
\hline Outcome Measure & Description & Interpretation \\
\hline Modified Fatigue Impact Scale (MFIS) & $\begin{array}{l}\text { 5-item tool included in the MS Quality of } \\
\text { Life Index (MS QLI) that assesses physical, } \\
\text { cognitive and psychosocial fatigue. }{ }^{(35-38)}\end{array}$ & $\begin{array}{l}\text { Scores range from } 0-20 \text {, with a lower } \\
\text { score indicating less fatigue }\end{array}$ \\
\hline Modified Ashworth Scale (MAS) & $\begin{array}{l}\text { Clinician reported outcome measure to score } \\
\text { spasticity in all } 4 \text { extremities. }\end{array}$ & $\begin{array}{l}\text { Scores range from } 0 \text { (no spasticity) to } 4 \\
\text { (severe spasticity) } \\
\text { A total score was calculated for each leg } \\
\text { A lower score indicates less spasticity }\end{array}$ \\
\hline MOS Pain Effects Scale & $\begin{array}{l}\text { 6-item participant reported questionnaire } \\
\text { included in the MS QLI to assess the degree to } \\
\text { which pain interferes with mood, and ability to } \\
\text { move, sleep, work, participate in recreation and } \\
\text { enjoy life. }\end{array}$ & $\begin{array}{l}\text { Scores range from } 6-30 \\
\text { A lower score indicates less pain }\end{array}$ \\
\hline Mental Health Inventory (MHI) & $\begin{array}{l}\text { 18-item participant reported questionnaire to } \\
\text { assess emotional and mental health }\end{array}$ & $\begin{array}{l}\text { Scores range from } 0 \text { to } 100 \\
\text { A higher score indicates the perception of } \\
\text { better mental health }\end{array}$ \\
\hline $\begin{array}{l}\text { Health Status Questionnaire } \\
\text { (HSQ or SF-36) }\end{array}$ & $\begin{array}{l}\text { 36-item participant reported questionnaire to } \\
\text { measure QOL included in the MS QLI. }\end{array}$ & $\begin{array}{l}\text { Scores range from } 0 \text { to } 100 \\
\text { A higher score indicates better QOL }\end{array}$ \\
\hline
\end{tabular}


TABle 2. Massage Routine in Prone (Participant positioned in prone, or in as close approximation to prone as possible within given comfort and ROM restrictions, bolster support as appropriate (4" foam wedge under ankles))

\begin{tabular}{|c|c|c|}
\hline Body Part (Time in min) & Stroke/Location & Details \\
\hline \multirow[t]{13}{*}{ Back (15) } & E, caudally beginning on superior aspect of shoulders, descending to iliac crest & 5 strokes \\
\hline & $\begin{array}{l}\text { E, hand-over-hand caudally on R side of back from superior aspect of shoulders to iliac crest, } \\
\text { followed by cephalically on R side of back from iliac crest to superior aspect of shoulders }\end{array}$ & 5 passes \\
\hline & $\mathrm{P}, \mathrm{R}$ side of back from iliac crest to superior scapula & 5 passes \\
\hline & $\mathrm{P}, \mathrm{R}$ upper trapezius from acromioclavicular joint to base of cervical spine & 5 passes \\
\hline & $\mathrm{P}$, perispinal musculature from base of cervical spine (C7) to occiput & 5 passes \\
\hline & $\mathrm{LF}$, caudally along lamina groove on $\mathrm{R}$ side from $\mathrm{C} 7$ to iliac crest & 5 strokes \\
\hline & $\begin{array}{l}\text { LF, from junction of lumbar spine (L5) and iliac crest to lat edge of quadratus lumborum, } \\
\text { R side }\end{array}$ & 5 strokes \\
\hline & $\begin{array}{l}\text { E, hand-over-hand caudally on L side of back from superior aspect of shoulders to iliac crest, } \\
\text { followed by cephalically on L side of back from iliac crest to superior aspect of shoulders }\end{array}$ & 5 passes \\
\hline & $\mathrm{P}, \mathrm{L}$ side of back from iliac crest to superior scapula & 5 passes \\
\hline & $\mathrm{P}, \mathrm{L}$ upper trapezius from acromioclavicular joint to base of cervical spine & 5 passes \\
\hline & $\mathrm{P}$, perispinal musculature from base of cervical spine (C7) to occiput & 5 passes \\
\hline & $\mathrm{LF}$, caudally along lamina groove on $\mathrm{L}$ side from $\mathrm{C} 7$ to iliac crest & 5 strokes \\
\hline & LF, from junction of L5 and iliac crest to lat edge of quadratus lumborum, L side & 5 strokes \\
\hline \multirow[t]{6}{*}{ Post RLE (7) } & E, from Achilles tendon to hamstring attachment. & 5 strokes \\
\hline & $\mathrm{P}$, on gastroc/soleus from Achilles tendon to 1" inferior to popliteal fossa & 5 passes \\
\hline & $\begin{array}{l}\text { E, hand-over-hand along med post thigh from med femoral condyle to 2" inferior to pubic } \\
\text { symphysis (adductors/hamstrings) }\end{array}$ & 5 passes \\
\hline & $\begin{array}{l}\text { P, med post thigh from med femoral condyle to } 2 \text { " inferior to pubic symphysis (adductors/ } \\
\text { hamstrings) }\end{array}$ & 5 passes \\
\hline & $\begin{array}{l}\text { E, hand-over-hand along lat post thigh from lat femoral condyle to greater trochanter } \\
\text { (hamstrings/IT band) }\end{array}$ & 5 passes \\
\hline & $\mathrm{P}$, lat post thigh from lat femoral condyle to greater trochanter (hamstrings/IT band) & 5 passes \\
\hline \multirow[t]{6}{*}{ Post LLE (7) } & $\mathrm{E}$, from Achilles tendon to hamstring attachment & 5 strokes \\
\hline & $\mathrm{P}$, gastroc/soleus from Achilles tendon to 1" inferior to popliteal fossa & 5 passes \\
\hline & $\begin{array}{l}\text { E, hand-over-hand med post thigh from med femoral condyle to } 2 \text { " inferior to pubic symphysis } \\
\text { (adductors/hamstrings) }\end{array}$ & 5 passes \\
\hline & $\begin{array}{l}\text { P, med post thigh from med femoral condyle to } 2 \text { " inferior to pubic symphysis } \\
\text { (adductors/hamstrings) }\end{array}$ & 5 passes \\
\hline & $\begin{array}{l}\text { E, hand-over-hand lat post thigh from lat femoral condyle to greater trochanter } \\
\text { (hamstrings/IT band) }\end{array}$ & 5 passes \\
\hline & $\mathrm{P}$, lat post thigh from lat femoral condyle to greater trochanter (hamstrings/IT band) & 5 passes \\
\hline
\end{tabular}

gliding stroke of superficial pressure performed with palmar surface of hands at a consistent rhythm with a smooth, continuous motion that did not lose contact with the skin until completion of a described stroke. Hand-over-hand effleurage (E, hand-over-hand) was applied according to this same description, but further defined as rhythmic alternation of hands at more rapid rate of speed (approximately one second each hand). Petrissage $(\mathrm{P})$ was defined as a lifting/kneading motion using a lumbrical grip of moderate pressure, resulting in the shifting of different muscular structures against one another, and/or of muscle tissue being lifted from underlying structures. Friction was applied using either linear friction (LF) or cross-fiber friction (XFF). LF was defined as deep pressure using pad of thumbs with compressive force along length of muscle; XFF was defined as deep pressure using pad of thumbs or fingers bidirectionally across the grain of musculature, superficial layers of tissue moving over deeper muscles. Static Compression (SC) was applied using deep pressure with the pad of thumbs statically, intended to pin a trigger point nodule, adhered tissue, or otherwise identified area of tissue dysfunction against deeper tissue or bone. SC was generally held for 8-12 s, but longer and shorter duration holds were performed at therapist discretion. Participants received this specific routine of MT for approximately $1 \mathrm{hr}$ each week, for six weeks, in a quiet room, on a massage table, by a licensed massage therapist (LMT).

Two primary LMTs and one investigator were trained in the MT routine. Two of the study investigators, also LMTs, filmed a video of delivery 


\section{BACKUS: IMPACT OF MT ON MS PATIENTS}

TABLE 3. Massage Routine in Supine (Participant positioned in supine, or in as close approximation to supine as possible within given comfort and ROM restrictions, bolster support as appropriate (4" foam wedge under knees). Five minutes allowed for transition from prone to supine.)

\begin{tabular}{|c|c|c|}
\hline Body Part (Time in min) & Stroke/Location & Details \\
\hline \multirow[t]{6}{*}{ Ant RLE (7) } & E, 1" superior to med/lat malleoli to ASIS & 5 strokes \\
\hline & LF, along tibialis ant & 5 strokes \\
\hline & $\begin{array}{l}\text { E, hand-over-hand, med thigh from 1" superior to med femoral condyle to } 2 \text { " } \\
\text { inferior to pubic symphysis }\end{array}$ & 5 passes \\
\hline & $\begin{array}{l}\text { P, med ant thigh from med femoral condyle to } 2 \text { " below pubic symphysis } \\
\text { (adductors/quadriceps) }\end{array}$ & 5 passes \\
\hline & E hand-over-hand, lat thigh from 1" superior to lat femoral condyle to ASIS & 5 passes \\
\hline & $\mathrm{P}$, lat ant thigh from lat femoral condyle to greater trochanter (quadriceps/IT band) & 5 passes \\
\hline \multirow[t]{6}{*}{ Ant LLE (7) } & E from 1" superior to med/lat malleoli to ASIS & 5 strokes \\
\hline & LF, along tibialis ant & 5 strokes \\
\hline & $\begin{array}{l}\text { E, hand-over-hand, med thigh from } 1 \text { " superior to med femoral condyle to } 2 \text { " inferior } \\
\text { to pubic symphysis }\end{array}$ & 5 passes \\
\hline & $\begin{array}{l}\text { P, med ant thigh from med femoral condyle to 2" below pubic symphysis } \\
\text { (adductors/quadriceps) }\end{array}$ & 5 passes \\
\hline & E, hand-over-hand, lat thigh from 1" superior to lat femoral condyle to ASIS & 5 passes \\
\hline & $\mathrm{P}$, lat ant thigh from lat femoral condyle to greater trochanter (quadriceps/IT band) & 5 passes \\
\hline \multirow[t]{6}{*}{ RUE (7) } & $\begin{array}{l}\text { E, forearm from wrist crease to } 1 \text { " inferior to cubital fossa, alternating hands to cover } \\
\text { full ant/post surfaces of forearm }\end{array}$ & 5 strokes each side \\
\hline & $\begin{array}{l}\text { P, using single hand on forearm from wrist crease to } 1 \text { " inferior to cubital fossa } \\
\text { (opposing hand stabilizes arm) }\end{array}$ & 5 passes \\
\hline & $\begin{array}{l}\text { E, prox arm from 1" superior to cubital fossa to humeral head, alternating hands to } \\
\text { cover full ant/post surfaces of prox } \text { arm }^{\mathrm{a}}\end{array}$ & 5 stokes each side \\
\hline & P, using single hand on prox arm from 1" superior to cubital fossa to humeral head ${ }^{\mathrm{a}}$ & 5 passes \\
\hline & E along pectoralis major/ant surface of arm from inferior to clavicle to hand & 5 strokes \\
\hline & $\begin{array}{l}\text { Light kneading pressure using pad of thumbs on palmar surface of hand (hand } \\
\text { supported on therapist's hands) }\end{array}$ & $30 \mathrm{~s}$ \\
\hline \multirow[t]{6}{*}{ LUE (7) } & $\begin{array}{l}\text { E, forearm from wrist crease to } 1 \text { " inferior to cubital fossa, alternating hands to cover } \\
\text { full ant/post surfaces of forearm }\end{array}$ & 5 strokes each side \\
\hline & $\begin{array}{l}\text { P using single hand on forearm from wrist crease to } 1 \text { " inferior to cubital fossa } \\
\text { (opposing hand stabilizes arm) }\end{array}$ & 5 passes \\
\hline & $\begin{array}{l}\text { E, prox arm from 1" superior to cubital fossa to humeral head, alternating hands to } \\
\text { cover full ant/post surfaces of prox arm }\end{array}$ & 5 passes \\
\hline & P, using single hand on prox arm from 1" superior to cubital fossa to humeral head & 5 passes \\
\hline & E, along pectoralis major/ant surface of arm from inferior to clavicle to hand & 5 strokes \\
\hline & $\begin{array}{l}\text { Light kneading pressure using pad of thumbs on palmar surface of hand (hand } \\
\text { supported on therapist's hands) }\end{array}$ & $30 \mathrm{~s}$ \\
\hline \multirow[t]{8}{*}{ Neck/Head and Shoulders (8) } & E, occiput to acromioclavicular joint on the $\mathrm{R}$ & 5 strokes \\
\hline & LF, occiput to $\mathrm{C} 7$ & 5 strokes \\
\hline & LF, C7 to acromioclavicular joint & 5 strokes \\
\hline & $\begin{array}{l}\text { XFF to sub-occipitals on the R } 15 \mathrm{~s} \\
\text { SC to sub-occipitals on R } 15 \mathrm{~s}\end{array}$ & \\
\hline & E, occiput to acromioclavicular joint on the $\mathrm{L}$ & 5 strokes \\
\hline & LF, occiput to $\mathrm{C} 7$ & 5 strokes \\
\hline & LF, C7 to acromioclavicular joint & 5 strokes \\
\hline & $\begin{array}{l}\text { XFF to suboccipitals on the R } 15 \mathrm{~s} \\
\text { SCto suboccipitals on } \mathrm{L} 15 \mathrm{~s}\end{array}$ & $30 \mathrm{~s}$ \\
\hline
\end{tabular}

a If subject is able, arm positioned behind head with shoulder flexion and elbow flexion; if unable, arm remains by side.

Ant = anterior; $\mathrm{LF}=$ linear friction; $\mathrm{E}=$ effleurage; $\mathrm{E}$, hand-over-hand = effleurage, hand-over-hand; $\mathrm{L}=$ left; Lat $=$ lateral; $\mathrm{LE}=$ lower extremity; Med = medial; Min = minutes; $\mathrm{P}=$ Petrissage; $\mathrm{XFF}=$ Cross-fiber friction; $\mathrm{SC}=$ static compression; Post $=$ posterior; Prox $=$ proximal; $\mathrm{R}=$ right; $\mathrm{s}=$ seconds. 
of the specified routine for training. The LMTs first viewed this video and, once familiar with the routine, they performed it on two volunteers. One investigator observed the session to assess adherence to the routine and to provide feedback related to timing and sequencing. Once the LMTs demonstrated competency with the routine, the LMTs began providing this routine to participants for the study. Specific instructions were not given regarding speed of strokes; the speed of each stroke was implied in the overall time period associated with the body area addressed. Level of pressure was determined relative to participant tolerance, particularly with the techniques of petrissage, linear friction, and static compression. All attempts were made to assure that the same primary LMT administered all six massages on a given participant. However, if a primary LMT was not available for some reason, the other primary LMT or the trained investigator administered the MT for that session.

At the completion of each session, the LMT completed the Process Evaluation Form (Table 4), to indicate any deviation from the routine during that session. The Process Evaluation Forms were reviewed by a coinvestigator weekly to ascertain the routine was followed by the LMT. If there were any deviations to the protocol, the coinvestigator followed up with the LMT to discuss and resolve any issues. In addition, the study coordinator and a coinvestigator reviewed these data sheets regularly to make sure that all data points were complete. If a data point was missing, the study coordinator contacted the LMT to determine if the data point could be captured, and the principal investigator was notified. In all cases, the data were retrieved from the LMT and documented.

If a massage was stopped for any reason and the participant had received less than 30 min of the 1 -hour massage, they were rescheduled for another session. If the massage lasted for at least 30 consecutive minutes, the massage was deemed complete and another session was not scheduled. If a participant missed a session, every attempt was made to reschedule this session during the same week of the missed session. If that was not possible, then the massage was rescheduled at the end of all of the sessions. All six sessions for massage were completed within an eightweek period. If a participant withdrew or dropped out of the study, another participant was recruited to replace them. The only exception was that one of the last participants dropped out of the study at the time of her final massage and would not return for testing. Another participant was not recruited given that the study time period (one year) had ended.

\section{Analysis}

All data were collected on paper forms and kept in a locked cabinet. Data were entered into an Excel spreadsheet and a statistical software program (SPSS version 15.0 for Windows) by a study co-investigator and checked for quality and completeness by the principal investigator.

We employed descriptive statistics to evaluate means and standard deviations. Paired $t$ tests were used to determine statistically significant differences pre- and postintervention in fatigue (MFIS), pain (MOS Pain) and spasticity (MAS), perception of health (MHI), and QOL (HSQ). Correlational analyses were conducted to examine the relationship between fatigue, pain, and spasticity, perception of health (MHI) and QOL (HSQ). We employed Spearman's rho correlation coefficients to estimate correlation coefficients to determine if there was

TABle 4. Process Evaluation Form

Massage Weekly Process Evaluation Form

Therapist Session Number Date

1) Effects of last massage / "subjective"

2) Current Pain level: VAS and location prior to massage

3) Was patient position altered from standard prone and supine? No Yes (if yes how)

4) Massage routine: sequence change? No Yes (if yes, please note how and why)

5) Massage routine: pacing change? No Yes (if yes, please note how and why)

6) Massage routine: skip items? No Yes (if yes, please note how and why)

7) Did you complete the massage routine? No Yes (if no, please describe why)

8) Deviation from protocol (something added?) No Yes (if yes, please note below)

9) Session ends on time No Yes

10) Please note anything else pertinent to the session evaluation that may not have been covered in the previous questions.

11) Current Pain level: VAS and location post to massage

Before say goodbye

Next appointment date confirmed No Yes 
a relationship between changes in symptoms and participant reports of health and QOL. Statistical significance was determined with a value equal to or less than alpha level of 0.05 .

In addition, we analyzed the data to assess clinically meaningful change, using the definition: "Clinically meaningful change can be defined as a noticeable, appreciable difference that is of value to the patient or the health professional, and that exceeds variation attributable to chance."(41) Based on Cohen, effect sizes of 0.2 are considered small, $0.5-0.6$ are considered medium, and 0.8 are considered large. ${ }^{(42)}$

\section{RESULTS}

\section{Participants}

Twenty-eight individuals with MS were enrolled in this study, and 24 completed all MT sessions and outcome measures. The majority $(n=22)$ were female, the mean age was 47.38 years (range $=24-71$, standard deviation $(\mathrm{SD})=13.05)$, and the mean time since diagnosis was 12.68 years (range $=2-25$ years, $\mathrm{SD}=6.13$ ). Two participants did not know the time since diagnosis. Two participants dropped from the study due to transportation or family issues, one due to medical reasons, and a fourth was dropped due to no longer meeting the enrollment criteria after being enrolled. There were no adverse events in this study.

\section{Fatigue, Pain, and Spasticity}

Table 4 presents the findings from the paired $t$ tests. Twenty-two of the 24 participants reported a decrease in fatigue. There was a significant decrease in MFIS scores from pre- to post-testing $(p<.01)$, indicating a decrease in self-reported fatigue after the intervention. One participant reported no change after the intervention, and one reported a slight increase (total score 13 pre and 15 post). There also was a significant $18 \%$ decrease in pain $(p<.01)$ as indicated by the MOS Pain scores after the intervention.

A complete MAS was collected on 19 of the 24 participants. Five participants were not assessed due to timing of the assessment, transportation issues, and evaluator unavailability. Only 16 of those 19 reported any spasticity at the onset of the study, with scores ranging from 1 (slight increase in muscle tone, manifested by a catch and release or by minimal resistance at the end of the range of motion when the affected part(s) is moved in flexion or extension) to 3 (considerable increase in muscle tone, passive movement difficult) for these participants. There was no significant increase or decrease in the MAS in this group after the intervention in either the left or right leg ( $p=.17$ and .23 , respectively).

Effect sizes (ES) for measures of fatigue, pain, and spasticity are found in Table 5. There was a large negative ES for MFIS and MOS Pain, and a small negative ES for MAS, both right and left leg.

Table 5. Descriptive Statistics, Comparison of Means Using Paired $t$ Tests, and Effect Sizes Using Cohen's $d(\mathrm{n}=24)$

\begin{tabular}{|c|c|c|c|c|c|c|c|}
\hline & Pre & Post & & Paired 1 & ifferences & & \\
\hline $\begin{array}{c}\text { Measure } \\
\text { (Range of Scores) }\end{array}$ & $\begin{array}{c}\text { Mean } \\
(S D, S E \text { Mean })\end{array}$ & $\begin{array}{c}\text { Mean } \\
(S D, S E \text { Mean })\end{array}$ & Mean & $S D$ & SE Mean & $p$ & Cohen's d $\mathrm{d}^{a}$ \\
\hline $\begin{array}{l}\text { Modified Fatigue Impact Scale } \\
(0-20)\end{array}$ & $12.00(3.67,0.75)$ & $7.92(3.65,0.74)$ & 4.08 & 4.03 & .823 & $<.01$ & -1.01 \\
\hline $\begin{array}{l}\text { MOS Pain Effects Scale } \\
(6-30)\end{array}$ & $18.46(5.79,1.18)$ & $13.92(4.74,0.98)$ & 4.54 & 5.96 & 1.22 & $<.01$ & -0.76 \\
\hline $\begin{array}{l}\text { Mental Health Inventory } \\
(0-100)\end{array}$ & $64.95(13.34,2.72)$ & $78.24(11.96,2.44)$ & -13.29 & 10.62 & 2.17 & $<.01$ & 1.25 \\
\hline \multicolumn{8}{|l|}{$\begin{array}{l}\text { Health Status Questionnaire } \\
(0-100)\end{array}$} \\
\hline Total Score & $91.58(12.27,2.51)$ & $103.00(14.55,2.97)$ & -11.13 & 13.64 & 2.79 & $<.01$ & 0.93 \\
\hline General Health & $55.08(10.84,2.21)$ & $55.71(13.73,2.80)$ & -3.63 & 12.04 & 2.46 & .15 & 0.30 \\
\hline Physical Functioning & $37.50(21.87,4.46)$ & $42.71(25.02,5.11)$ & -5.21 & 25.39 & 5.18 & .33 & 0.21 \\
\hline Role-Physical & $20.83(24.08,4.92)$ & $51.04(37.94,7.74)$ & -30.21 & 42.97 & 8.77 & $<.01$ & 0.70 \\
\hline Bodily Pain & $39.04(20.76,4.24)$ & $56.38(19.45,3.97)$ & -17.33 & 16.66 & 3.40 & $<.01$ & 1.04 \\
\hline Role-Emotional & $45.75(35.27,7.20)$ & $70.83(35.86,7.31)$ & -25.08 & 40.83 & 8.34 & .01 & 0.61 \\
\hline Vitality & $35.21(18.68,3.81)$ & $51.04(17.57,3.59)$ & -15.83 & 19.37 & 3.96 & $<.01$ & 0.82 \\
\hline Mental Health & $68.67(15.50,3.16)$ & $80.00(12.32,2.51)$ & -11.33 & 11.42 & 2.33 & $<.01$ & 0.99 \\
\hline Social Functioning & $60.42(26.50,5.41)$ & $75.00(23.02,4.70)$ & -14.83 & 27.75 & 5.66 & .02 & 0.53 \\
\hline
\end{tabular}

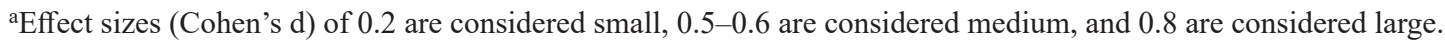
$\mathrm{SD}=$ standard deviation; SE Mean = standard error of the mean. 


\section{Perception of Health and Quality of Life}

All participants $(n=24)$ completed the MHI and HSQ. There was a significant increase in the total MHI $(p<.01)$ and in all subscales of the MHI as well, indicating an overall improvement in mental health. However, there were some participants who did not improve on the anxiety subscale $(\mathrm{n}=3)$, depression subscale $(\mathrm{n}=1)$, and the positive affect subscale $(\mathrm{n}=$ 3 ). Two experienced a decrease in both the Behavior Control and Positive Affect subscale.

There was a significant increase in the Role-Physical $(p<.01)$, Bodily Pain $(p<.01)$, Role-Emotional $(p=$ $.01)$, Vitality $(p<.01)$, Mental Health $(p<.01)$, and Social Functioning $(p=.02)$ subscales of the HSQ, indicating an improvement in these aspects of QOL.

There was a large ES for the MHI and all subscales of the HSQ, except for the HSQ General Health and Physical subscales, which were small, and the Emotional and Social subscales, which were medium.

\section{Relationships Between Measures}

Table 6 provides details regarding the correlations between measures. Significant correlations include change in total MFIS score being positively correlated with total MOS Pain change score $(r=0.532, p=.01)$. Furthermore, change in MFIS score was negatively correlated with total MHI change $(r=-0.647, p<.01)$ and the change scores for the Physical Functioning $(r=-0.544, p=.01)$, Role-Physical $(r=-0.576, p<$ $.01)$, Bodily Pain $(r=-0.57, p<.01)$, Role-Emotional $(r=-0.543, p=.01)$ and Social $(r=-0.519, p=.01)$ subscales of the HSQ. This indicates that as fatigue decreased, these measures of QOL increased (i.e., improved). Change in total MOS Pain score was negatively correlated with total MHI score $(r=-0.584$, $p<.01)$ and Role-Physical subscale of the HSQ ( $r=$ $-599, p<.01)$, also indicating that as pain decreased, these measures of QOL increased. There were no other statistically significant relationships between fatigue (MFIS), pain (MOS Pain), and health (MHI) or QOL (HSQ) measures.

\section{DISCUSSION}

This pilot study is the first to demonstrate the positive impact of a standardized massage therapy (MT) routine on fatigue and pain, as well as perception of health and quality of life (QOL) in individuals with MS. These findings are meaningful given the prevalence of fatigue and pain in people with MS, and the extent to which these symptoms impact an individual's perception of health and QOL. ${ }^{(8,10,17)} \mathrm{We}$ failed to find a similar reduction of spasticity after MT in our participants with MS.

Our finding that fatigue and pain were both significantly decreased in our participants with MS after MT is not surprising given that MT has been shown to decrease fatigue and pain in people with chronic fatigue syndrome ${ }^{(32)}$ and fibromyalgia syndrome, ${ }^{(31)}$ both chronic diseases significantly impacting the health and well-being of individuals in a fashion similar to MS.

The pathophysiology underlying fatigue in MS is unclear and each individual's experience of fatigue is different and variable over the course of the disease. Putative mechanisms being explored in an effort to better understand the pathophysiology of MS fatigue include the influence of proinflammatory cytokines, central nervous system lesion load, cortical atrophy and abnormal patterns of cerebral activation, poor

Table 6. Correlations Between Measures

\begin{tabular}{|c|c|c|c|c|c|c|c|c|c|}
\hline & $\begin{array}{l}\text { MOS } \\
\text { Pain }\end{array}$ & $M H I$ & $\begin{array}{l}\text { Physical } \\
\text { Function }\end{array}$ & $\begin{array}{c}\text { Role- } \\
\text { Physical }\end{array}$ & $\begin{array}{c}\text { Bodily } \\
\text { Pain }\end{array}$ & $\begin{array}{c}\text { Role } \\
\text {-Emotional }\end{array}$ & Vitality & $\begin{array}{l}\text { Mental } \\
\text { Health }\end{array}$ & $\begin{array}{c}\text { Social } \\
\text { Function }\end{array}$ \\
\hline MFIS & $.532^{\mathrm{a}}$ & $-.647^{\mathrm{a}}$ & $-.544^{\mathrm{a}}$ & $-.576^{\mathrm{a}}$ & $-.572^{\mathrm{a}}$ & $-.543^{\mathrm{a}}$ & $-.619^{\mathrm{a}}$ & -.245 & $-.519^{a}$ \\
\hline MOS Pain & & $-.584^{\mathrm{a}}$ & -.197 & $-.599^{a}$ & -.361 & -.363 & -.158 & -.208 & -.385 \\
\hline MHI & & & .375 & $.561^{\mathrm{a}}$ & .308 & $.576^{\mathrm{a}}$ & $.487^{\mathrm{b}}$ & $.686^{\mathrm{a}}$ & $.670^{\mathrm{a}}$ \\
\hline \multicolumn{10}{|c|}{ Health Status Questionnaire } \\
\hline Physical Function & & & & $.431^{\mathrm{b}}$ & $.463^{\mathrm{b}}$ & .283 & $.583^{\mathrm{a}}$ & .136 & .331 \\
\hline Role -Physical & & & & & .270 & $.497^{\mathrm{b}}$ & .209 & .217 & $.512^{\mathrm{b}}$ \\
\hline Bodily Pain & & & & & & .130 & $.483^{\mathrm{b}}$ & .052 & .340 \\
\hline Role-Emotional & & & & & & & $.574^{\mathrm{a}}$ & .233 & $.484^{\mathrm{b}}$ \\
\hline Vitality & & & & & & & & .382 & $.475^{\mathrm{b}}$ \\
\hline Mental Health & & & & & & & & & $.595^{\mathrm{a}}$ \\
\hline
\end{tabular}

${ }^{\mathrm{a}} \mathrm{p}<.01$

${ }^{\mathrm{b}} \mathrm{p}<.05$ 
endocrine influences and axonal injury. ${ }^{(43)}$ In addition, muscle fatigue has also been demonstrated in people with $\mathrm{MS}^{(44)}$ and may contribute to the overall fatigue reported by individuals with MS. Thus, this lack of clarity related to fatigue in MS makes it difficult to understand the potential mechanisms by which MT may have a positive impact on fatigue. ${ }^{(45-48)}$

MT has also been shown to be effective for decreasing neuropathic pain in some people with spinal cord injury. ${ }^{(27)}$ Roberts ${ }^{(28)}$ reported that light to moderate massage led to a decrease in the gain of the spinal nociceptive reflexes, which are often elevated in chronic pain syndromes. Although we did not explore potential mechanisms for the changes seen in our participants with MS, MT may also be effective in decreasing pain in people with MS through mechanisms similar to those described by Roberts. ${ }^{(28)}$

As fatigue and pain increase in people with MS, QOL decreases. ${ }^{14,17-19)}$ The fact that we found that decreases in fatigue and pain are related to improvements in perception of health and QOL is meaningful, considering that at this time there is neither a cure for MS, nor an adequate treatment for fatigue or pain for people with MS. Furthermore, medications for management of fatigue and pain are costly, and MT may provide a relatively inexpensive and accessible option for decreasing these symptoms and, thereby, improve perception of health and QOL in people with MS.

Although others have demonstrated a decrease in spasticity after a massage intervention in individuals with neurological disorders, ${ }^{(21)}$ we did not find a significant decrease in spasticity in our participants with MS. One explanation is that earlier studies evaluated spasticity immediately or within $30 \mathrm{~min}$ following an MT session, ${ }^{(21)}$ and we only assessed spasticity at the end of the six-week intervention period and not immediately following a single MT session. Furthermore, the MT routine appeared to be different than the one utilized for our study. For instance, although Malila et al. ${ }^{(29)}$ reported a decrease in spasticity, they utilized a Thai massage; Goldberg et al. ${ }^{(30)}$ found benefits only with a deep tissue massage using a one-handed petrissage technique; Brouwer and de Andrade ${ }^{(21)}$ utilized slow stroking. The MT routine in our study employed both petrissage and effleurage techniques. Perhaps, had we used the same type of massage as employed in these earlier studies, we might have seen a different response in their spasticity. However, it is important to note that the literature related to massage and spasticity is small and the reports variable.

A significant finding from this study is that the MT routine provided did not increase spasticity in our participants. Only three of our participants actually reported spasticity at the onset of the study, and hence this may explain the lack of improvement. Another potential explanation for not finding a reduction in spasticity in our study participants is that the outcome measure we used to assess spasticity, the Modified
Ashworth Scale, only assesses whether there is hypertonia or a velocity dependent resistance to stretch, ${ }^{(34)}$ whereas other studies utilized tests of H-reflex excitability $^{(21,30)}$ or joint range of motion. ${ }^{(21,49)}$ The fact that our participants did not experience a significant decrease in spasticity may be because we did not use a targeted intervention to directly address the muscles having spasticity, which we have previously shown decreased spasticity in one person with spinal cord injury. ${ }^{(33)}$ Further research is warranted to assess the long-term effects on spasticity utilizing other MT approaches in people with MS.

Limitations of this study include the small size and the lack of a control group. In addition, while all attempts were made to standardize the delivery of the massage routine provided in this study, we did not control for the amount of pressure provided. This would be an important consideration for future studies, given that there is evidence that different amounts of pressure can elicit unique responses. ${ }^{(49-51)}$

Other variables not studied in this study include depression $^{(52)}$ and sleep disorders, both common symptoms reported by people with MS. Both have been shown to influence fatigue in people with MS, and both have been reported to decrease after MT in other patient populations. A careful consideration of depression and sleep disorders would be warranted in future studies.

\section{CONCLUSION}

These findings suggest that massage therapy is a safe and potentially beneficial intervention for people with MS. Considerations for clinical application include the ability to comfortably position individuals with mobility restrictions. Concerns related to MS often include the risk of causing an increase in symptoms, such as fatigue, pain or spasticity. However, this study showed that not only is MT safe for people with MS, but also that it may be an important adjunctive therapy, given that traditional approaches often do not ameliorate their symptoms.

If MT can decrease fatigue and pain in some people with MS, this would provide at least some people with MS improved well-being and QOL. Given the state of health care reimbursement, providing evidence to support the use of interventions is critical in order to get paid for those interventions. This issue is even more important for people with MS, who have a chronic disease and resulting long-term health care needs.

\section{CONFLICT OF INTEREST NOTIFICATION}

This work was funded by the Massage Therapy Foundation. There are no other conflicts of interest for any of the authors. 


\section{COPYRIGHT}

Published under the CreativeCommons AttributionNonCommercial-NoDerivs 3.0 License.

\section{REFERENCES}

1. Compston A, Coles A. Multiple sclerosis. Lancet. 2008;372(9648):1502-1517. http://www.sciencedirect.com/ science/article/pii/S0140673608616207

2. Frohman TC, Castro W, Shah A, Courtney A, Ortstadt J, Davis $\mathrm{SL}$, et al. Symptomatic therapy in multiple sclerosis. Ther Adv Neurol Disord. 2011;4(2):83-98. http://tan.sagepub.com/ content/4/2/83.long

3. Amato MP, Ponziani G, Rossi F, Liedl CL, Stefanile C, Rossi L. Quality of life in multiple sclerosis: the impact of depression, fatigue and disability. Mult Scler. 2001;7(5):340-344. http:// msj.sagepub.com/content $/ 7 / 5 / 340$.long

4. Janardhan V, Bakshi R. Quality of life in patients with multiple sclerosis: the impact of fatigue and depression. J Neurol Sci. 2002;205(1):51-58. http://www.sciencedirect.com/science/ article/pii/S0022510X0200312X

5. Bakshi R. Fatigue associated with multiple sclerosis: diagnosis, impact and management. Mult Scler. 2003;9(3):219-227. http:// msj.sagepub.com/content/9/3/219.long

6. Schreurs KM, de Ridder DT, Bensing JM. Fatigue in multiple sclerosis: reciprocal relationships with physical disabilities and depression. J Psychosom Res. 2002;53(3):775-781. http://www. sciencedirect.com/science/article/pii/S0022399902003264

7. Bakshi R, Shaikh ZA, Miletich RS, Czarnecki D, Dmochowski $\mathrm{J}$, Henschel K, et al. Fatigue in multiple sclerosis and its relationship to depression and neurologic disability. Mult Scler. 2000;6(3):181-185. http://msj.sagepub.com/content/6/3/ 181.long

8. Krupp LB. Fatigue in multiple sclerosis: definitions, pathophysiology, and treatment. CNS Drugs. 2003;17(4):225-234. https://www.ncbi.nlm.nih.gov/pubmed/12665396

9. Pittion-Vouyovitch S, Debouverie M, Guillemin F, Vandenberghe N, Anxionnat R, Vespignani H. Fatigue in multiple sclerosis is related to disability, depression and quality of life. J Neurol Sci. 200615;243(1-2):39-45. http://www.sciencedirect.com/ science/article/pii/S0022510X05004387

10. Svendsen KB, Jensen TS, Overvad K, Hansen HJ, Koch-Henriksen N, Bach FW. Pain in patients with multiple sclerosis: a population-based study. Arch Neurol. 2003;60(8):1089-1094. http:// archneur.jamanetwork.com/article. aspx?articleid=784508

11. Beiske AG, Pedersen ED, Czujko B, Myhr KM. Pain and sensory complaints in multiple sclerosis. Eur J Neurol. 2004;11(7):479-482. http://onlinelibrary.wiley.com/ doi/10.1111/j.1468-1331.2004.00815.x/full

12. Solaro C, Brichetto G, Amato MP, Cocco E, Colombo B, D'Aleo G, et al. The prevalence of pain in multiple sclerosis: a multicenter cross-sectional study. Neurology. 2004;63(5):919921. http://www.neurology.org/content/63/5/919.long

13. Österberg A, Boivie J, Thuomas KA. Central pain in multiple sclerosis - prevalence and clinical characteristics. Eur J Pain. 2005;9(5):531-531. http://onlinelibrary.wiley.com/ doi/10.1016/j.ejpain.2004.11.005/full
14. Rizzo MA, Hadjimichael OC, Preiningerova J, Vollmer TL. Prevalence and treatment of spasticity reported by multiple sclerosis patients. Mult Scler. 2004;10(5):589-595. http://msj. sagepub.com/content/10/5/589.long

15. Barnes MP, Kent RM, Semlyen JK, McMullen KM. Spasticity in multiple sclerosis. Neurorehabil Neural Repair. 2003;17(1):66-70. http://nnr.sagepub.com/content/17/1/66.long

16. Beard SM, Hunn A, Wight J. Treatments for spasticity and pain in multiple sclerosis: a systematic review. 2003;7(40):1-111. http://eprints.whiterose.ac.uk/1776/1/Beard_1.pdf

17. Kalia LV, O'Connor PW. Severity of chronic pain and its relationship to quality of life in multiple sclerosis. Mult Scler. 2005;11(3):322-327. http://msj.sagepub.com/ content $/ 11 / 3 / 322$.long

18. Svendsen KB, Jensen TS, Hansen HJ, Bach FW. Sensory function and quality of life in patients with multiple sclerosis and pain. Pain. 2005;114(3):473-481. https://www.ncbi.nlm.nih. gov/pubmed/15777872

19. O'Connor AB. Neuropathic pain: quality-of-life impact, costs and cost effectiveness of therapy. Pharmacoeconomics. 2009;27(2):95-112. https://www.ncbi.nlm.nih.gov/ pubmed/19254044

20. Shakespeare DT, Boggild M, Young C. Anti-spasticity agents for multiple sclerosis. Cochrane Database Syst Rev. 2003;(4):CD001332. https://www.ncbi.nlm.nih.gov/ pubmed/14583932

21. Brouwer B, de Andrade VS. The effects of slow stroking on spasticity in patients with multiple sclerosis: a pilot study. Physiother Theory Pract. 1995;11(1):13-21.

22. Nayak S, Matheis RJ, Schoenberger NE, Shiflett SC. Use of unconventional therapies by individuals with multiple sclerosis. Clin Rehabil. 2003;17(2):181-191. http://cre.sagepub.com/ content/17/2/181.long

23. Olsen SA. A review of complementary and alternative medicine (CAM) by people with multiple sclerosis. Occup Ther Int. 2009;16(1):57-70. http://onlinelibrary.wiley.com/doi/10.1002/ oti.266/abstract

24. Hernandez-Reif M, Field T, Field T, Theakston H. Multiple sclerosis patients benefit from massage therapy. J Bodyw Mov Ther. 1998;2(3):168-174. http://www. complementarytherapiesinmedicine.com/article/S09652299(99)80060-0/abstract

25. Schroeder B, Premkumar K, Doig J. The effects of massage therapy on Multiple Sclerosis patients. BMC Complement Altern Med.2012;12(Suppl 1):P225. http://bmccomplementalternmed. biomedcentral.com/articles/10.1186/1472-6882-12-S1-P225

26. Hernandez-Reif M, Field T, Largie S, Diego M, Manigat N, Seoanes J, et al. Cerebral palsy symptoms in children decreased following massage therapy. Early Child Dev Care. 2005;175(5):445-456. http://www.idibidikids.com.au/Cerebral_Palsy_Symptoms_in Children_Decreased_Following_Massage_Therapy.pdf

27. Norrbrink C, Lundeberg T. Acupuncture and massage therapy for neuropathic pain following spinal cord injury: an exploratory study. Acupunct Med. 2011;29(2):108-115. http://aim. bmj.com/content/29/2/108.long

28. Roberts L. Effects of patterns of pressure application on resting electromyography during massage. Int $J$ Ther Massage Bodywork. 2011;4(1):4. http://www.ncbi.nlm.nih.gov/pmc/ articles/PMC3088531/ 
29. Malila P, Seeda K, Machom S, Eungpinithpong W. Effects of Thai massage on spasticity in young people with cerebral palsy. J Med Assoc Thailand. 2015;98(Suppl 5):S92-S96. https:// www.ncbi.nlm.nih.gov/pubmed/26387418

30. Goldberg J, Sullivan SJ, Seaborne DE. The effect of two intensities of massage on H-reflex amplitude. Phys Ther. 1992;72(6):449-457. http://ptjournal.apta.org/ content/72/6/449.long

31. Sunshine W, Field TM, Quintino O, Fierro K, Kuhn C, Burman I, et al. Fibromyalgia benefits from massage therapy and transcutaneous electrical stimulation. $J$ Clin Rheumatol. 1996;2(1):18-22. https://www.ncbi.nlm.nih.gov/ pubmed/19078022

32. Field TM, Sunshine W, Hernandezreif M, Quintino O, Schanberg S, Kuhn C, et al. Massage therapy effects on depression and somatic symptoms in chronic fatigue syndrome. JChronic Fatigue Syndr. 1997;3(3):43-51. http://www.tandfonline.com/ doi/abs/10.1300/J092v03n03_03?journalCode=icfs20

33. Manella C, Backus D. Gait characteristics, range of motion, and spasticity changes in response to massage in a person with incomplete spinal cord injury: case report. Int J Ther Massage Bodywork. 2011;4(1):28. http://www.ncbi.nlm.nih.gov/pmc/ articles/PMC3088529/

34. Bohannon RW, Smith MB. Interrater reliability of a modified Ashworth scale of muscle spasticity. Phys Ther. 1987;67(2):206-207. http://ptjournal.apta.org/content/ ptjournal/67/2/206.full.pdf

35. Ritvo PG, Fischer JS, Miller DM, Andrews H, Paty DW, LaRocca NG. Multiple Sclerosis Quality of Life Inventory: a User's Manual. New York: National Multiple Sclerosis Society; 1997.

36. Potter K, Cohen ET, Allen DD, Bennett SE, Brandfass KG, Widener GL, et al. Outcome measures for individuals with multiple sclerosis: recommendations from the American Physical Therapy Association Neurology Section Task Force. Phys Ther. 2014;94(5):593-608. http://ptjournal.apta.org/content/ ptjournal/94/5/593.full.pdf

37. Schwid SR, Covington MMSB, Segal BM, Goodman AD. Fatigue in multiple sclerosis: current understanding and future directions. J Rehabil Res Dev. 2002;39(2):211-224. https:// www.ncbi.nlm.nih.gov/pubmed/12051465

38. Flachenecker P, Kümpfel T, Kallmann B, Gottschalk M, Grauer O, Rieckmann P, et al. Fatigue in multiple sclerosis: a comparison of different rating scales and correlation to clinical parameters. Mult Scler. 2002;8(6):523-526. http://msj.sagepub. com/content/8/6/523.long

39. Sherman KF, Dixon MW, Thompson D, Cherkin DC. Development of a taxonomy to describe massage treatments for musculoskeletal pain. BMC Complement Altern Med. 2006;6:24. http:/www.ncbi.nlm.nih.gov/pmc/articles/PMC1544351/

40. Archer P, Chandler C, Garbowski R, Lochhaas T, O’Hara J, Ribeiro C, et al. The Core: Entry-Level Analysis Project Report. 2013. http://www.elapmassage.org/_files/ELAP_Blueprint.pdf. Accessed June 17, 2016.
41. Eisen SV, Ranganathan G, Seal P, Spiro III A. Measuring clinically meaningful change following mental health treatment. J Behav Health Serv Res. 2007;34(3):272-289. http://link. springer.com/article/10.1007\%2Fs11414-007-9066-2

42. Cohen J. Statistical Power for the Behavioral Sciences. Hillsdale, NJ: Laurence Erlbaum and Associates; 1988.

43. Induruwa I, Constantinescu CS, Gran B. Fatigue in multiple sclerosis - a brief review. J Neurol Sci. 2012;323(1):915. http://www.sciencedirect.com/science/article/pii/ S0022510X12004364

44. Steens A, Heersema DJ, Maurits NM, Renken RJ, Zijdewind I. Mechanisms underlying muscle fatigue differ between multiple sclerosis patients and controls: a combined electrophysiological and neuroimaging study. Neuroimage. 2012;59(4):3110-3118. http://www.sciencedirect.com/science/ article/pii/S105381191101319X

45. Krupp L. Fatigue is intrinsic to multiple sclerosis (MS) and is the most commonly reported symptom of the disease [editorial]. Mult Scler. 2006;12(4):367-368. http://msj.sagepub.com/ content/12/4/367.long

46. Lerdal A, Celius EG, Krupp L, Dahl AA. A prospective study of patterns of fatigue in multiple sclerosis. Eur J Neurol. 2007;14(12):1338-1343. http://onlinelibrary.wiley.com/ doi/10.1111/j.1468-1331.2007.01974.x/full

47. Giovannoni G. Multiple sclerosis related fatigue. J Neurol Neurosurg Psychiatry. 2006;77(1):2-3. http://www.ncbi.nlm. nih.gov/pmc/articles/PMC2117414/

48. Comi G, Leocani L, Rossi P, Colombo B. Physiopathology and treatment of fatigue in multiple sclerosis. J Neurol. 2001;248(3):174-179. http://link.springer.com/article/10.1007/ s004150170222

49. Diego MA, Field T. Moderate pressure massage elicits a parasympathetic nervous system response. Int $J$ Neurosci. 2009;119(5):630-638.

50. Billhult A, Määttä S. Light pressure massage for patients with severe anxiety. Complement Ther Clin Pract. 2009;15(2):96-101.

51. Field T, Diego M, Hernandez-Reif M. Moderate pressure is essential for massage therapy effects. Int $J$ Neurosci. 2010;120(5):381-385.

52. Wood B, Van Der Mei IAF, Ponsonby AL, Pittas F, Quinn S, Dwyer T, et al. Prevalence and concurrence of anxiety, depression and fatigue over time in multiple sclerosis. Mult Scler. 2013;19(2):217-224. http://msj.sagepub.com/ content/19/2/217.full.pdf + html

Corresponding author: Deborah Backus, Shepherd Center, 2020 Peachtree Rd. NW, Atlanta, GA 30309, USA

E-mail: deborah_backus@shepherd.org 